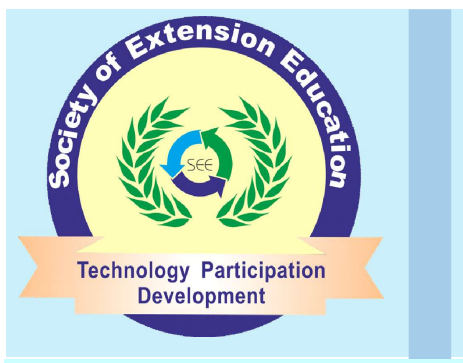

Research Note

\section{Indian Research Journal of Extension Education}

ISSN: 0972-2181 (Print), 0976-1071 (Online)

NAAS Rating : 5.22

Journal homepage: seea.org.in

https://doi.org/10.54986/irjee/2022/jan_mar/131-133

\title{
Academic Stress among Rural Adolescents due to COVID -19 : A Comparative Analysis
}

\author{
Sheetal ${ }^{1}$ and Suman Audichya ${ }^{2}$ \\ 1. PG Scholar, 2. Prof., Human Development and Family Studies, CCSc, MPUA\&T, Udaipur, Rajasthan, India. \\ Corresponding author e-mail : sheoransheetal98@gmail.com
}

Paper Received on August 17, 2021, Accepted on November 06, 2021 and Published Online on January 01, 2022

\begin{abstract}
Adolescence is a period during which individuals' transit from puberty to adulthood. Children go through many changes throughout this time, including biological, cognitive, and emotional changes. Excessive stress caused by studies, high expectations, and lack of capacity to maintain studies is referred to as academic stress. The study's major goal was to assess the academic stress among rural adolescents owing to COVID-19. The study was conducted in Udaipur district of Rajasthan. For the sample selection from four villages having Sr. Sec, schools were randomly selected. From selected schools, 180 students of age group of 16-18 years were selected randomly. The sample consisted equal no. of adolescent boys and adolescent girls. Slightly modified Academic stress scale developed by Rao (2012) was used to assess academic stress in adolescent boys and girls. Collected data was further classified, in tabulated form and analyzed through using suitable statistical measures. Results indicated that adolescents' boys and girls faced moderate to high academic stress. Furthermore, girls were facing high academic stress as compared to boys.
\end{abstract}

Key words: Academic stress; Adolescent; COVID-19.

$\mathbf{W}_{\text {e all are aware from the fact that Corona virus }}$ (COVID 19) spread immediately around the globe has significantly impact on every individual life. Adolescents were one of the age groups that affected the most. This was a novel setting for young children, which increased their stress level. Education institutions in the country have shifted considerably from personal and classroom teaching to online teaching-learning practices. In a very short span, the lives of students have altered dramatically as they have to leave their campuses, adapt to new settings and adapt to online courses. The move to online learning is likely to raise the stress of students, especially in courses that have not been initially intended for online delivery. Practical training aimed at increasing personal engagement with practical experiences has a higher disadvantage in terms of evaluation, leading to lower levels of proficient learners, more mental stress and poor autonomy. Some students might have problems navigating computers and the internet at home, in particular those living in remote regions. According to the research, $17 \%$ of students cannot perform homework tasks, as they have no access to internet (Terada, 2020). Adolescents who were studying in secondary and senior secondary schools were most fragile group. Exams, grades, homework, academic and achievement expectations are the most significant stressors for high school and intermediate students.

Stressors are defined as factors that disrupt or 
threaten an individual's daily routine functioning and force them to make changes whereas, stress is an unpleasant state of emotional and physiological arousal that people experience when they perceive a situation to be dangerous or threatening to their well-being (Laney et. al., 2008). In the present situation, not every student in rural areas has access to the newest internet content and equipment available to students in metropolitan cities. This has created the major academic, emotional and psychological challenges among the students who come from rural areas. Thus, the present study was planned to compare the academic stress experienced by rural boys and girls with objective i.e. To study and compare the academic stress of rural adolescent boys and girls between 16- 18 years of age due to COVID -19 pandemic.

\section{METHODOLOGY}

The present study was conducted on the basis of 'Descriptive Research design' in Udaipur, a district of Rajasthan to find out the level of educational satisfaction among the rural adolescents (both boys and girls). From Udaipur district, Panchayati samiti was selected randomly. For the selection of sample, four villages namely Bedwas, Debari, Bhoyo ki Pancholi, and Manvakheda, were selected randomly having government senior secondary schools. Separate list of boys and girls were prepared in age of 16 to 18 years from all four schools. 90 boys and 90 girls were selected from each location randomly. Total sample consisting of 180 rural adolescents. Academic stress of adolescents was assessed by using the Academic stress scale developed by Rao (2012) was slightly modified and used. Calculate statistical inference Frequency, per centages, mean, standard deviation and ' $Z$ ' test were computed. The academic stress inventory consists of 28 elements divided into four dimensions. Furthermore, from the gathered data, each dimension of academic stress and overall academic stress were coded separately for boys and girls. A score of one was assigned for a "Yes" response and two for a "No" response (Table.1).

Table 1. Score range for overall academic stress level

\begin{tabular}{ll}
\hline Low level & $1-19$ \\
\hline Average level & $20-37$ \\
High level & $38-56$ \\
\hline
\end{tabular}

As a result, each item received a maximum score of 2 and a minimum value of 1 . As a result, the higher the score, the more academic stress there is, and the lower the score, the less academic stress there is.

\section{RESULTS AND DISCUSSION}

Data for distribution of respondents for their academic stress and it's dimension as per gender is given in Table 2. Results showed that due to academic expectations average level of stress was present in 62.2 per cent boys and 56.6 per cent girls, while high level of stress was reported in 43.3 per cent girls and 37.7 per cent boys. None of the respondents found in low stress level in this dimension. Higher per centage of girls were reported in high level of stress category because of aspiration to score good grades and they had more anxiety about result after the examination. Data showed that 35.5 per cent girls and 33.3 per cent boys were under high examination stress, while 64.4 per cent girls and 66.6 per cent boys were having average academic stress. In this dimension, none of the participants had a low stress level. Boys (36.3\%) and girls (43.3\%) were highly stressful due to lack of facilities at home but average academic stress was found in 63.3 per cent boys and 56 per cent girls. None of the adolescent experienced low stress under this dimension. Girl students were reported highly stressful due to dearth of proper facilities such as lack of access to computer, inadequate study material available, and inability to concentrate during study hours due to home environment. Due to online education, considerable academic stress was noted in boys (48.8 \%) and girls (47.7\%); average study stress was found in 51.1 and 52.2 per cent of boys and girls, respectively. Further results revealed that overall high academic stress was found in boys $(42.2 \%)$ and girls (46.6\%) whereas, average academic stress was reported in 57.7 per cent boys and 53.3 per cent adolescents' girls. Under low academic stress category, none of the respondents were noted. Numerous other researches also unveiled that there exists a significant difference in academic stress of boys and girls' students. (Chandra, 2020, Vandana and Duhan, 2020)

Comparison of academic stress as per gender: $\mathrm{Z}$ test was computed to examine whether there existed differences in academic stress on the basis of gender (Table 3.) Results highlighted statistically significance difference in academic expectation $(Z=2.79 *)$ at 0.05 level of significance. Mean score reveals that adolescent 
Table 2. Distribution of respondents for academic stress and its dimensions

\begin{tabular}{llllllll}
\hline Dimensions & & $\begin{array}{r}\text { Low } \\
\text { No. \% }\end{array}$ & \multicolumn{2}{c}{$\begin{array}{c}\text { Av. } \\
\text { No. } \%\end{array}$} & \multicolumn{2}{c}{$\begin{array}{l}\text { High } \\
\text { No. \% }\end{array}$} \\
\hline Academic expectations & Boys & - & - & 56 & 62.2 & 34 & 37.7 \\
& Girls & - & - & 51 & 56.6 & 39 & 43.3 \\
Examination stress & Boys & - & - & 60 & 66.6 & 30 & 33.3 \\
& Girls & - & - & 58 & 64.4 & 32 & 35.5 \\
Facilities available & Boys & - & - & 57 & 63.3 & 33 & 36.3 \\
at home & Girls & - & - & 51 & 56 & 39 & 43.3 \\
Online classes & Boys & - & - & 46 & 51.1 & 44 & 48.8 \\
& Girls & - & - & 47 & 52.2 & 43 & 47.7 \\
Overall academic stress & Boys & - & - & 52 & 57.7 & 38 & 42.2 \\
& Girls & - & - & 48 & 53.3 & 42 & 46.6 \\
\hline
\end{tabular}

Table 3. Comparison of academic stress level of adolescent boys and girls $(\mathrm{N}=\mathbf{1 8 0})$

\begin{tabular}{llll}
\hline Dimension & & Mean $\pm \mathrm{SD}$ & $\mathrm{Z}$ value \\
\hline Academic expectations & Boys & $9.1 \pm 1.23$ & $2.79^{*}$ \\
& Girls & $9.7 \pm 1.62$ & \\
Examination stress & Boys & $9 \pm 1.14$ & $2.89^{*}$ \\
& Girls & $9.6 \pm 1.6$ & \\
Facilities at home & Boys & $9 \pm 1.18$ & $4.36^{*}$ \\
& Girls & $9.9 \pm 1.56$ & \\
Online classes & Boys & $9.4 \pm 1.5$ & $1.33^{\mathrm{NS}}$ \\
& Girls & $9.69 \pm 1.42$ & \\
Overall & Boys & $36.6 \pm 3.26$ & $3.69^{*}$ \\
& Girls & $38.9 \pm 4.98$ & \\
\hline
\end{tabular}

*Significance at 0.05 per cent level girls $(M=9.7)$ had higher academic expectation than adolescent boys $(M=9.1)$. Statistically significance difference was observed in examination stress $\left(\mathrm{Z}=2.89^{*}\right)$ at 0.05 level of significance. Girls $(M=9.6)$ had higher examination stress than adolescent boys $(\mathrm{M}=9)$ according to mean score levels. Academic stress level on basis of facilities available at home for study was found significantly higher $\left(\mathrm{Z}=4.36^{*}\right)$ in the girls than the boys. They were devoid of many facilities that were available for the boys. Statistically significant difference $\left(\mathrm{Z}=4.36^{*}\right)$ was observed in stress level between the boys and girls, this difference was due to facilities available at home ( 0.05 level of significance). Girls $(\mathrm{M}=9.9)$ had higher mean score as compared to boys $(\mathrm{M}=9)$ according to mean score level. No significant difference was observed with online classes against gender

\section{CONCLUSION}

From the results of the study, it may be concluded that majority of adolescents had average level of academic stress followed by high academic stress level. None of the student had low stress level. Higher per centage of boys were observed in average categories stress level, while in high level of academic stress category, girls per centage was higher in comparison to the boys.

\section{CONFLICTS OF INTEREST}

The authors declare that they have no conflicts of interest.

\section{REFERENCES}

Chandra, Y. (2020). Online education during COVID-19: perception of academic stress and emotional intelligence coping strategies among college students. Asian Edu. and Devel.Studies, 10 (2) : 229-238

Jyothi, V. and Vijayabhinandana (2021). A scale to measure the attitude of students towards online learning. Indian Res.J.Ext. Edu., 21 (2\&3) : 37-42

Laney, C.; Morris, E.K.; Bernstein, D.M.; Wakefield, B.M. and Loftus, E.F. (2008). Asparagus, a love story: Healthier eating could be just a false memory away. Experimental Psycho., 55 : 291- 300.

Malik, A.K. and Godara, A.K. (2020). Information and Communication Technologies(ICTs) use by the students of CCSHAU, Hisar. Indian Res.J.Ext. Edu., 20 (4) : 28-33

Rao, R.B. (2012). A study of academic stress and adjustment styles of teacher trainees. Scale of academic stress. 235-237.

Terada, Y. (2020). Covid-19's : Impact on K-12 students' academic and mental well-being Edutopia (https://www.edutopia.org/ article/covid-19s-impact-students-academic-and-mental-well-being )

Vandana and Duhan, K. (2020). Comparative study on academic Stress among adolescents as per gender. Intl. Archive of Applied Sci. and Tech., 11 (2) : 98-101 